\title{
Effects of One-a-Day Foot Patrols on Hot Spots of Serious Violence and Crime Harm: a Randomised Crossover Trial
}

\author{
Lewis Basford ${ }^{1} \cdot$ Chris Sims $^{2} \cdot$ lain Agar $^{1} \cdot$ Vincent Harinam $^{2} \cdot$ Heather Strang $^{2}$ \\ Published online: 6 September 2021 \\ (C) The Author(s) 2021
}

\section{Abstract}

Research Question Does one foot patrol per day (15-20 min) conducted in serious violence harm spots reduce street-visible crime harm and frequency relative to no foot patrol in the same hot spots, and if so by how much?

Data We identified 20 hot spots of $150 \mathrm{~m}^{2}$ each on the basis of community violence defined as serious assaults, robbery, and drug dealing in the Southend-on-Sea area of Essex Police, with boundaries geo-fenced to collect GPS measures of foot patrol presence generated by hand-held electronic trackers issued to officers directed to perform patrols. All street-visible crimes were counted for each of the 90 days of the experiment in each hot spot.

Methods Daily random assignment of each hot spot to either control or treatment conditions $(N=90$ X $20=1800$ place-days) prescribed 720 place-days to receive extra patrols by Operational Support Group officers, which were compared to 1080 place-days with no extra patrols, using an intent-to-treat design, with $98 \%$ compliance with assigned treatments. Independent measures of other police presence in the area were tracked by the force-wide GPS telematics measures. All crimes were coded with the Cambridge Crime Harm Index for their CHI value.

Findings The 20 harm spots comprised just $2.6 \%$ of the geographical area of the Southend-on-Sea area, with $41 \%$ of all its Cambridge CHI crime harm in the year preceding the experiment. Background patrol presence was about 2 min per day on control days and $1 \mathrm{~min}$ per treatment day. Crime harm scores for serious community violence were $88.5 \%$ lower on experimental days with extra patrols (mean $=1.07 \mathrm{CHI}$ per treatment place-day) than without it (mean $=9.30 \mathrm{CHI}$ per control place-day). Crime harm scores for all street-visible offences were $35.6 \%$ lower on treatment days

Heather Strang

hs404@cam.ac.uk

1 Essex Police, Essex, UK

2 University of Cambridge, Cambridge, UK 
$($ mean $=7.94 \mathrm{CHI}$ per treatment place-day) than control days $($ mean $=12.33 \mathrm{CHI}$ per control place-day), while the mean count of all street-visible offences was $31 \%$ lower on treatment days (mean count $=0.09$ crimes per treatment place-day) than on control days (mean count $=0.13$ crimes per control place-day). The estimated effect of the 720 days with 15-min patrols was to prevent crimes with recommended imprisonment of 3161 days, or 8.66 years.

Conclusion The use of two-officer foot patrol can be highly effective at preventing serious violence in street-visible settings in small areas in which such violence is heavily concentrated.

Keywords Foot patrol $\cdot$ Hot spots $\cdot$ Residual deterrence $\cdot$ Crime harm index $\cdot$ Randomised experiment $\cdot$ Street-visible crime $\cdot$ Crossover design

\section{Introduction}

This study reports on a practitioner-led randomised controlled trial of one-a-day foot patrols in Southend-on-Sea, Essex, between 20th July 2020 and 17th October 2020. The study sought to test high visibility foot patrol on street-based violence within the most harm-generating locations. The 20 highest harm spots of $150 \mathrm{~m}^{2}$ were selected for intervention. The harm spots represented just $2.6 \%$ of Southend's geographical area but contributed disproportionately to crime harm for community violence over the preceding 12 months, with $41 \%$ of all Cambridge Crime Harm Index (Sherman, Neyroud \& Neyroud, 2016) harm for offences in the 12-month period leading to March 2020.

Officers from the Essex Police Operational Support Group were tasked to drive to the designated harm spots, park their police car in a highly visible location, and undertake foot patrol for $15 \mathrm{~min}$. All officers were subject to a briefing that covered the research literature on hot spots policing, different types of intervention, and reasons that a community-based approach had been chosen for this study. Officers were also briefed on the electronic tracker's capability to plot their whereabouts every $5 \mathrm{~s}$. Daily feedback was then provided on the previous day's visits and crime levels.

During two-officer foot patrols within the harm spots, officers were directed to undertake a minimum of $15 \mathrm{~min}$ and a maximum of $20 \mathrm{~min}$ of foot patrol with the police vehicle parked in a prominent and visible position. Officers were further guided to engage with the public in conversation and adopt a public engagement approach rather than seeking enforcement opportunities such as stop and account or stop and search (unless presented with spontaneous incidents or information that required police intervention).

\section{Background: Hot Spots Policing}

The concept of hot spots policing began with the observation that $3 \%$ of places in Minneapolis were responsible for $50 \%$ of all calls for service (Sherman et al., 1989). Other studies since then have found similar observations and similar concentrations of crimes in micro-locations, especially for serious violence. Essex Police recently observed that $37 \%$ of all knife-enabled offences in the last 3 years took place in just $0.4 \%$ 
of all $200 \mathrm{~m}$ street segments and $60 \%$ of all community violence took place within $0.8 \%$ of all $200 \mathrm{~m}$ street segments (Essex Police, 2020).

These concentrations of high harm in a tiny fraction of all places invited experiments in concentrating police presence in the same fraction (e.g. Sherman \& Weisburd, 1995). Systematic reviews of over 40 experiments have identified the crime control benefits of hot spots policing from 1989 to 2017 (Braga et al., 2014, 2019). Yet widespread implementation remains stagnant in most police forces across England and Wales. In her address to the Police Foundation in 2015 by then-Chair of the National Police Chiefs Council, Chief Constable Sara Thornton, she stated, "Hot spot policing is one of the strongest examples of using research to improve policing and, therefore, being able to demonstrate effectiveness" (National Police Chiefs Council, 2016). Yet even in 2021, we do not see wholesale implementation of this idea in any UK police force.

\section{What Should Police Be Doing at Crime Hot Spots to Reduce Violent Crime?}

Braga et al. $(2014,2019)$ observed a mounting mass of research signifying an evidence base for directed police patrol and proactive and targeted arrests as well as a problem-orientated policing (POP) approach. One example is the Braga et al.'s (1999) randomised controlled experiment with the Jersey City Police Department to evaluate problem-oriented policing (POP) approaches through the allocation of twenty-four high crime intersections, split into twelve pairs of similar crime output, with one intersection of each pair receiving treatment and the other control conditions. The POP saw all 12 treatment locations receive aggressive order maintenance policing, supplemented with other interventions such as drug enforcement, cleaning of shop fronts, street cleaning, enhanced lighting, and eviction of troubling tenants. In total, there were 28 different treatments used in the 12 treatment areas. The varying use of all 28 treatments were analysed in the study, but it could not show which of the treatments had the optimal impact. Analysed results revealed a significant reduction at treatment locations against control for both total crime count, which varied throughout all six crime indicators (including robbery, assaults, and narcotics) as well as calls for service (street fight, nuisance/disorder, drugs [Braga et al., 1999]).

In the summer of 2009, in Philadelphia, 200 police officers across 60 violent hotspots implemented a randomised controlled trial to test the effectiveness of foot patrol against violent crime. The experiment found substantial reductions in crime, with treatment locations reducing counts of violent crimes compared to control locations by $23 \%$ (Ratcliffe et al., 2011).

\section{Residual Deterrence}

While foot patrol was the exclusive treatment in the Philadelphia trial, two recent and supportive studies suggest the additional benefit of "residual deterrence" (Barnes et al., 2020; Ariel et al., 2020) and the temporal "free bonus" (Sherman, 1990) period of sustained deterrence after the policing activity has ceased. The Barnes et al.'s (2020) "so what" question in their Western Australia study was "how minimal can minimalist patrol be?" What they were asking is how minimal can patrol be to get optimum residual deterrence. Their experiment produced a $41.6 \%$ reduction in crime harm through an average of 13.8 min of patrol per patrol day, in a "crossover" design 
comparing the same hot spots on days with and without short patrols (on bikes, on foot, or in cars - any kind of patrols. The experiment by Ariel et al. (2020) in the London Underground showed that 2-officer foot patrols on higher-crime Tube station trackside platforms reduced crime all over the station, including at the level of the turnstiles many feet up from the platforms. They also reduced crime on days when there was no patrol, relative to a fixed control group that never received these patrols.

One of the best-known discoveries was Koper's (1995) observational study of data from the Minneapolis preventative patrol study (Sherman \& Weisburd, 1995), which found the optimal patrol length for residual deterrence to be $15 \mathrm{~min}$ — with diminishing returns on investment at greater lengths of patrol. Koper (1995), and more recently, Ariel et al. (2020) also demonstrated that the main element of deterrence occurred postpatrol and when police were not present. Ariel et al. (2020) showed that $97 \%$ of the total effect of foot patrols on crime prevention in the London Underground study occurred when police were not present, but in places where they did patrol regularly (and unpredictably).

The Barnes et al. (2020) study also showed a distinct "cliff edge" of residual deterrence with noticeable increases in crime after 4 days of no patrol and after an average of just $13.8 \mathrm{~min}$ of presence preceding those no-patrol days. This finding underlines the need for further studies in today's environment of increased implementation of hot spots policing.

\section{Crime Count vs Crime Harm}

The use of a crime harm index is essential to policing experiments on reducing streetvisible violence. The recognition that all crimes are not created equal, and of the need for a Crime Harm Index (Sherman, 2013), has seen sustained progress towards organisational adoption in recent years. Specific indexes have been created in recent years that encompass harm relative to all crime, including a court records approach (Francis et al., 2005), an assessment of harm framework (Greenfield \& Paoli, 2013), a sentencing gravity score (Ratcliffe, 2015), and a crime victim survey score (Ignatans \& Pease, 2015). It is the Cambridge Crime Harm Index (CCHI), however, (Sherman, Neyroud \& Neyroud, 2016) that has evolved and developed in policing organisations throughout the UK and across the world (Mitchell, 2017; Braga et al., 2014, 2019; House \& Neyroud, 2018; Karrholm et al., 2020).

Reasons for a more consistent adoption of the Cambridge Crime Harm Index include its simplicity of application, consistent metrics of sentencing start points, and costneutral application within an organisation (Sherman et al., 2016). The Cambridge Crime Harm Index consistent metric is taken from sentencing guidelines and the starting point of the total days in prison a first-time offender convicted of that offence would receive. The starting point removes other uncontrollable metrics such as how many previous offences a suspect had previously been convicted of, first point guilty pleas, or other mitigating circumstances presented to the court, which in real-life application would see each person convicted of the same crime receiving varying sentence lengths (Sherman, et al. 2020).

Although significant progression has been made in the quest to present clarity of the data recorded by police and a true reflection of public safety, there remains a reluctance 
to move away from traditional crime counts and raw numbers. Sherman et al. (2020) therefore proposed further precision in counting crime through seven statistical series for counting crime usefully while remaining informative to the public and more useful for police decision making.

At present, the UK is utilising multiple methods with crime count remaining prevalent but complemented by the Cambridge Crime Harm Index (Sherman et al., 2016) and the Office of National Statistics (ONS) "Severity Score" index (ONS, 2020). The ONS Severity Score is seen as a backward-facing assessment with the average sentences for offences calculated from the previous 5 years data held by the Ministry of Justice. Although sentences would have been adjudicated through the judiciary with previous offending, mitigating, and aggravating factors being presented, Sherman et al. (2016) suggested, and the ONS (2020) remarks in its limitations, that the ONS approach is open to the current "judicial and public mood" with recent cases seeing a move towards stronger sentences for assaults against emergency workers, knife crimes, and noxious substance assaults. When considering its implementation and associated cost to the public purse, the ONS Severity Score requires continued investment to capture and collate the data, compared to the cost neutral application of the CCHI.

\section{Research Question}

Does one foot patrol per day (of 15 to $20 \mathrm{~min}$ ) conducted in serious violence harm spots reduce street-visible crime harm and frequency relative to no foot patrol in the same hot spots, and if so by how much?

\section{Data}

We identified 20 hot spots of $150 \mathrm{~m}^{2}$ each on the basis of community violence defined as serious assaults, robbery, and drug dealing in the Southend-on-Sea area of Essex Police, with boundaries geo-fenced to collect GPS measures of foot patrol presence generated by hand-held electronic trackers issued to officers directed to perform patrols. All street-visible crimes were counted for each of the 90 days of the experiment in each hot spot.

\section{Methods}

\section{Setting}

Southend-on-Sea is a coastal town with a population of $183,100(89,100$ males, 93,300 females), which doubles with daily visitors during the months of June, July, and August. Additional social data provided by Southend-on-Sea District Council reveals that there are 5700 households within the district that contain occupants who are all unemployed, which equates to $10.6 \%$ of all households against $14.6 \%$ nationally. 


\section{Sample Selection: Targeting Harm Spots of Community Violence}

The identification and selection of crime harm spots was performed in four steps. First, a crime query for violence and associated crimes led to the following section criteria in the ATHENA crime records system. First, the categories of violence with injury, robbery, and drug trafficking were the "community violence" crimes used to select the areas of concentration. Domestic abuse offences were excluded because they generally occur indoors out of the sight of police patrols. Second, the data analysis period was the 12 months to 23rd March 2020, the official date of the COVID-19 lockdown in the UK. An ATHENA enquiry indicated that there were 1381 offences in total for Southend-on-Sea contributing to a cumulative CHI harm total of 283,546 years of recommended imprisonment. The breakdown is displayed in Table 1 below:

Third, a KDE (kernel density estimation) hotspot technique was used to identify clusters of crime within a 150-m area, weighted by the crime harm index to create harm spots. In Southend-on-Sea, most hotspots of violence were highly clustered or around "hot points" rather than being dispersed. Violence in Southend-on-Sea is intensely clustered in the central business district/town centre areas.

Fourth, an additional test was undertaken to identify which harm spots were created by extremely low frequency of very high harm events, which typically would be a geographically isolated assault with intent to cause serious harm (1* Grievous Bodily Harm). Any harm spot clusters with less than 4 eligible crimes, equivalent to less than 1 offence every 12 weeks, were omitted. Figure 1 illustrates several harm spots where there is no clustering of violence offences within $100 \mathrm{~m}$. Two of the main harm spots that were excluded are Southend University Hospital and Southend Police Station as we already knew that geo-coding errors generated clusters of crimes for these specific locations.

This method included the rule that where harm spots clustered, artificial grids were created based on centroids (coordinates) at the centre of the harm spots. The top 20 harm grids were selected for targeting as both control and treatment sites utilising the crossover design, with each one roughly $150 \mathrm{~m}$ in size with a $100-\mathrm{m}$ buffer (Fig. 2).

Within these grids, $20 \%$ of all violence and $41 \%$ of all harm were occurring in $2.6 \%$ of the geographic area for a total of 277 offences in 2019-2020.

Table 1 Southend-On-Sea community violence crime count and crime harm 2019-2020

\begin{tabular}{llll}
\hline Crime & Sub & Count & Harm \\
\hline VWI & GBH/Att murder & 111 & 165,710 \\
VWI & Other wounding & 967 & 22,151 \\
Robbery & Personal & 186 & 67,890 \\
Robbery & Business & 17 & 6205 \\
Drug trafficking & PWITS & 100 & $21,590.5$ \\
& & 1381 & 283,546 \\
\hline
\end{tabular}




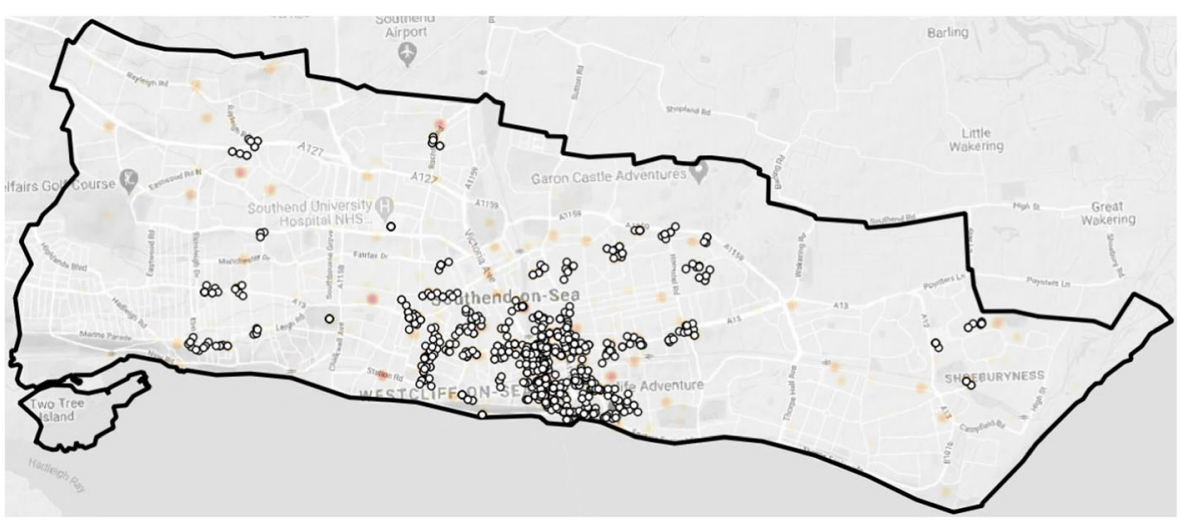

Fig. 1 Violent crime clusters with 4 or more offences within $100 \mathrm{~m}$

\section{Experimental Design}

The randomised allocation was completed using a pre-designed randomiser in Excel and set on day one of the experiment with no alterations during the 90-day period.

Over the 90-day study, each harm spot was defined by control or treatment through randomisation and analysed on the treatment based on its intended delivery, ensuring the studies review is based on the intention to treat (ITT) analysis. This ensures that any place-days that a treatment harm spot was not attended, it would remain, for purposes of analysis, within the treatment group for that day-and vice versa with place-days that were assigned to no-patrol control status but went on to receive patrol treatment in error.

\section{Implementation}

The eight harm spot allocations for each day were printed to give officers the location of only those harm spots requiring a visit for that day. The removal of other harm spots

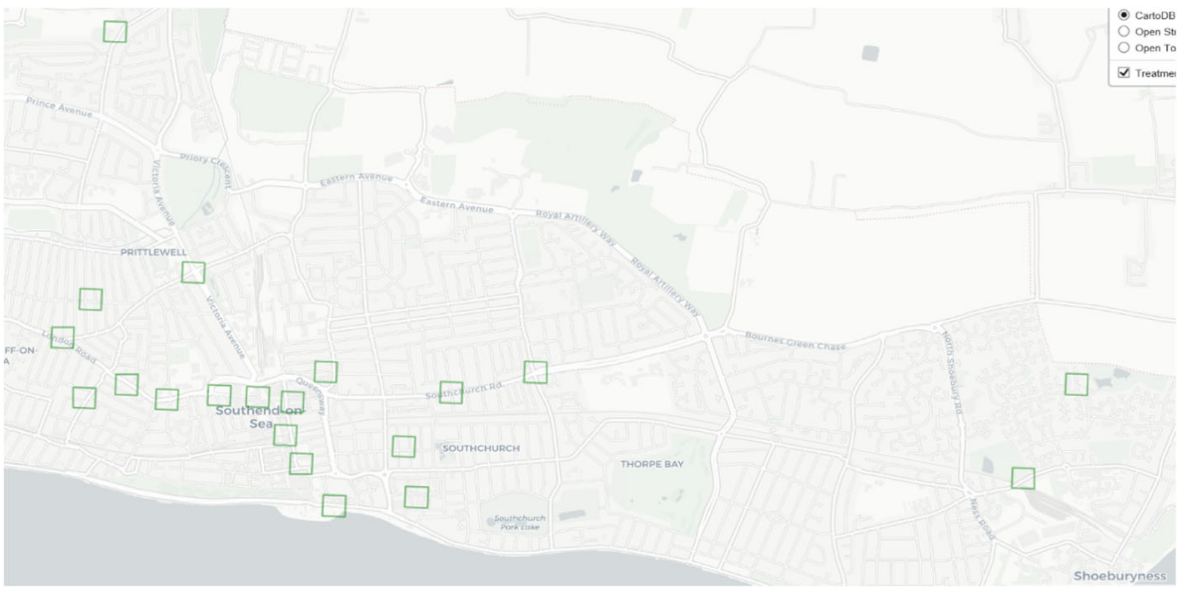

Fig. 2 The harm spots in Southend-On-Sea 
from the prints was to ensure a greater level of compliance. These prints were secured in a daily pack which was sealed at the point of randomisation. The packs were pre-printed each week and labelled by date with officers locating the pack and commencing patrol.

Officers were pre-allocated the overtime space to undertake the treatment. As such prior to the deployment, each officer was emailed the briefing as well as having a printed version within the pack. The briefing provided the officer with all the relevant details on what harm spots are and the theory behind the $15 \mathrm{~min}$ patrol period and incorporating the proposed benefits. The briefing also provided a template for officer returns and how to utilise the Global Positioning System (GPS) Tracker.

For this experiment, a "mission" was uploaded, for all 20 harm spots with scene photography and a geo-fenced area, onto the handheld device system. That system then sent an alert sound to the handheld device that officers were issued with to tell them that they were within the harm spot. Officers further developed this system during the deployment by adding markers for the optimum places to park the vehicle and any other location information that they felt may aid other officers attending the harm spot on a future treatment day. All officers had access to the software a backup aid was produced for officers to utilise, which was an application called "What 3 Words." That geographical locator software was pre-loaded within an Essex Police mobile handset or available privately on personal phones. This allowed the officers to confirm that they were always in the correct location.

Prior to the start of the trial, the first author briefed departments that would have direct impact on the trial such as the Force Control Room and Operational Support Group Commanders to ensure they understood the strict requirements around compliance and ring-fenced patrol status they were provided for the visits. This meant that a layer of authority on not removing the resource for anything other than immediate threat to life incidents was considered during deployments. Each department was then given a 15-min briefing by the first author, in conjunction with the lead analyst (third author), to provide a complete overview of the project and to answer questions from officers, such as "so what?" This briefing was also provided, in separate sessions, to communication officers on dispatch, control room inspectors, and local field supervisors within Southend. These efforts attempted to foster a better understanding of the rationale for the hot spots patrol resource being protected for the deployment period.

Tracking Tracking to measure whether officers were patrolling where they were deployed was monitored in three ways: GPS trackers with geo fence mapping panel notifications, the "telematics" system, and officer's written reports.

The body-worn GPS trackers given to each patrol pair had a dedicated mapping panel for recording location data every $5 \mathrm{~s}$. Predesigned geo-fenced harm spots were pre-loaded to track entry and exit times as well as speed of the tracker so that dip sampling of foot patrol could be undertaken.

The GPS trackers are small and compact at $70 \times 39 \times 20 \mathrm{~mm}$ and weigh only $65 \mathrm{~g}$ making them compact enough to add to the police equipment holsters. With up to 15 days battery life from a $2600 \mathrm{mAh}$ battery, the reliability for the periods covered by the officers guaranteed significant tolerance for capturing the treatment period. The GPS tracker utilises a multi-roaming SIM card connected to the best cell network at any given location, and recording data locations every $5 \mathrm{~s}$ on the mapping panel. Providing real-time management and oversight throughout the experiment, automated emails for 
entry and exit of the harm spots were sent to a dedicated email account which prompted a real-time monitoring of the treatment time that was being delivered.

\section{Measuring Other Patrol Presence: Telematics}

To measure the potential interference of treatment from other officers not working within the trial, a daily report from telematics (GPS data from all police vehicles) had been set up with its own geo-fenced area of all 20 harm spots. The telematics system provided a report on any police vehicle that remained within the harm spot for more than $90 \mathrm{~s}$. This report allowed for the discounting of vehicles on random patrol or passing through on emergency calls. Those vehicles within the harm spot for over $90 \mathrm{~s}$ were then manually reviewed and reported within the analysis as additional treatment/dosage.

As Fig. 3 shows, on control days, each harm spot received an average of 2 min and $5 \mathrm{~s}$ from officers either responding to emergency calls or on patrol. With control treatment days on average receiving only $32 \mathrm{~s}$ more than patrol treatment days, this finding provides strength in the validity of the treatments influence on the findings.

In addition to these two ways of collecting data (trackers and telematics) to benchmark against the technology being utilised, all officers returned a manual update via email to the dedicated email account providing their entry and exit times to the harm spot, vehicle fleet number (to be discounted against telematics), and other narrative information such as arrests, incidents that occurred and intelligence obtained and nature of the treatment actually delivered. This was descriptive in the words of the patrolling officer to gauge the public response and activity occurring within the harm spot. From an implementation outlook, this was a mechanism that focussed the officers on the core areas they had been asked to deliver in the harm spot and to ensure they carried it out to allow for a worthwhile return.

It must be noted that the use of an external GPS system for the tracking system (handheld device) is a bespoke product utilised for this study with no current emphasis in force on the use of GPS in tracking foot patrol on a day to day basis. This includes the internal GPS system (telematics) which in force was commissioned and funds obtained through the Home Office Innovation Fund with the focus on protecting officers against unfounded complaints, improving fleet management, improving operational deployment, and reducing demand on officers (the system removes the need for log books and mileage returns).

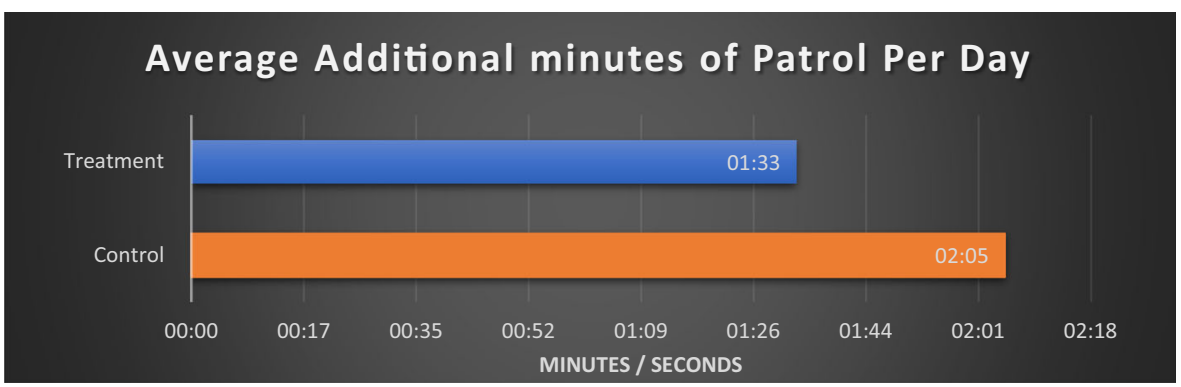

Fig. 3 Average additional minutes of patrol presence per day from other sources 


\section{Compliance}

Treatment days totalling 720 were assigned during the 90 days to receive a $15-20$-min foot patrol intervention. In total, there were 708 visits with just 12 uncompleted, which provides an overall compliance of $98.33 \%$ during the study period. From the officer submissions, narratives to support non-attendance were collated to understand reasons for non-attendance, most of which seemed unavoidable.

Findings These findings present outcomes from a 90-day randomised crossover trial in Southend-on-Sea conducted between 20th July 2020 and 17th October 2020, in which 720 treatment days totalling $220 \mathrm{~h}$ of foot patrol compared against 1080 control days were analysed. In these $220 \mathrm{~h}$, foot patrol prevented an estimated 4741 days of recommended imprisonment under English sentencing guidelines, or almost 13 years in prison, for all of the street-visible offences tracked in the experiment.

Three comparative measures were used to calculate the differences between treatment and control days: 1) sums and means of crime harm, and 2) of crime counts, as well as 3) the use of crime counts and crime harm totals with outliers removed. When analysing such police interventions as hot spots to aid comparison of the groups (treatment and control), the removal of outliers may provide a more typical measure of differences in offending between treatment groups (Table 2). This study's aim was to intervene with foot patrol in harm spots that were generated from the highest harm violent offences. Thus both harm and harm with outliers are analysed to understand the impact the study has had.

Table 3 shows that the mean number of community violence crimes $(\mathrm{GBH}$, assault, robbery, and drug dealing) counted on patrol days was $73 \%$ lower on days with patrol than on days without patrols. This translates into a Crime Harm CHI difference of a

Table 2 Available sample sizes on successive days of sequential assignment to the same condition-treatment or control

\begin{tabular}{|c|c|c|c|c|c|c|}
\hline & \multicolumn{3}{|c|}{ Control } & \multicolumn{3}{|c|}{ Treatment } \\
\hline & $\mathrm{N}$ & Percent & Cum. percent & $\mathrm{N}$ & Percent & Cum. percent \\
\hline 1st day & 435 & $40.2 \%$ & $40.2 \%$ & 433 & $60.2 \%$ & $60.2 \%$ \\
\hline 2nd day & 251 & $23.2 \%$ & $63.5 \%$ & 165 & $22.9 \%$ & $83.2 \%$ \\
\hline 3rd day & 157 & $14.5 \%$ & $78.0 \%$ & 66 & $9.2 \%$ & $92.4 \%$ \\
\hline 4th day & 91 & $8.4 \%$ & $86.4 \%$ & 27 & $3.8 \%$ & $96.1 \%$ \\
\hline 5 th day & 53 & $4.9 \%$ & $91.3 \%$ & 18 & $2.4 \%$ & $98.5 \%$ \\
\hline 6th day & 34 & $3.1 \%$ & $94.4 \%$ & 7 & $1.0 \%$ & $99.4 \%$ \\
\hline 7th day & 27 & $2.5 \%$ & $96.9 \%$ & 3 & $0.4 \%$ & $99.9 \%$ \\
\hline 8th day & 13 & $1.2 \%$ & $98.1 \%$ & 1 & $0.1 \%$ & $100.0 \%$ \\
\hline 9th day & 10 & $0.9 \%$ & $99.0 \%$ & & & \\
\hline 10th day & 6 & $0.6 \%$ & $99.5 \%$ & & & \\
\hline 11th day & 2 & $0.2 \%$ & $99.7 \%$ & & & \\
\hline 12th day & 2 & $0.2 \%$ & $99.9 \%$ & & & \\
\hline 13th day & 1 & $0.1 \%$ & $100.0 \%$ & & & \\
\hline Totals & 1080 & & & 720 & & \\
\hline
\end{tabular}


Table 3 Community violence on treatment and control days

Community violence

\begin{tabular}{llllll}
\hline & Control & Treatment & Diff. \% & $p$ & Effect size $^{\mathrm{a}}$ \\
\hline Sample size & 1080 & 720 & & & \\
Community violence & & & & & \\
Sum of crime harm & 10,045 & 770 & $-92.33 \%$ & N/A & N/A \\
Mean of crime harm per day & 9.3 & 1.07 & $-88.49 \%$ & $<0.01 * *$ & 0.81 \\
Sum of crime harm (outliers removed) & 4205 & 770 & $-92.9 \%$ & N/A & N/A \\
Mean of crime harm (outliers removed) & 3.89 & 1.07 & $-72.49 \%$ & $0.01 * *$ & 0.67 \\
Sum of crime count & 34 & 6 & $-81.1 \%$ & N/A & N/A \\
Mean of crime count & 0.03 & 0.008 & $-73.33 \%$ & $<0.001 * *$ & 1.6 \\
\hline
\end{tabular}

a Cohen's $d$

${ }^{b}$ Excludes any offences where the crime-harm value exceeds 3 years (1096 days) of recommended incarceration

$* p<0.05, * * p<0.01, * * * p<0.001$

mean of $\mathrm{CHI}=1.07$ per treatment day in the hot spots, compared to $\mathrm{CHI}=9.3$ in the same hot spots on control days. The difference is an $88.5 \%$ relative reduction in crime harm from the community violence offences, the reduction of which was the focus of the funding provided for the experiment.

Table 4 Street visible violence on treatment and control days

Street visible crimes

\begin{tabular}{llllll}
\hline & Control & Treatment & Diff. \% & $p$ & Effect Size $^{\mathrm{a}}$ \\
\hline Sample size & 1080 & 720 & & & \\
Street visible crimes & & & & & \\
Sum of crime harm & 13,316 & 5717 & $-57.1 \%$ & N/A & N/A \\
Mean of crime harm & 12.33 & 7.94 & $-35.6 \%$ & 0.11 & 0.18 \\
Sum of crime harm (outliers removed) & 5651 & 1702 & $-69.88 \%$ & N/A & N/A \\
Mean of crime harm (outliers removed) & 5.23 & 2.36 & $-54.88 \%$ & $0.03 *$ & 0.26 \\
Sum of crime count & 139 & 63 & $-54.86 \%$ & N/A & N/A \\
Mean of crime count & 0.13 & 0.09 & $-31 \%$ & $<0.001 * * *$ & 0.66 \\
\hline
\end{tabular}

a Cohen's $d$

${ }^{b}$ Excludes any offences where the crime-harm value exceeds 3 years (1096 days) of recommended incarceration

$* p<0.05, * * p<0.01, * * * p<0.001$ 


\section{All street visible crime}

As Table 4 shows, for all street-visible crime, the mean count of all street-visible crimes per day was $31 \%$ lower on treatment days (at 0.09 ) than on control days (at 0.13). This count difference masked an even larger difference in CHI harm, in which $35.6 \%$ lower harm was reported on patrol days (mean $\mathrm{CHI}=7.94$ days) than on control days (mean $\mathrm{CHI}$ $=12.33$ days). (The foregoing summary relies on all cases, with no outliers removed.)

Table 4 shows the most comprehensive evidence about the impact of the foot patrol on all types of crime and crime harm that are theoretically deterrable by police presence on public streets. It is the appropriate basis for calculating the cost-effectiveness of the $220 \mathrm{~h}$ of patrol delivered in the 90-day test. This calculation requires an adjustment for the different numbers of days in the treatment and control conditions. That adjustment can be done as follows.

Adjustment for Unequal Days in Treatment and Control Taking the finding of a mean level of 7.94 days of harm from street-visible crime in the patrol status, we can subtract that value from the mean of $12.33 \mathrm{CHI}$ days of harm on days in the control group status. The result shows that on each patrol day, a mean of (12.33-7.94=) 4.39 days of CHI-measured harm was saved on each patrol place-day, with 15-20 min of patrol. Since the experiment actually assigned the patrols on 720 treatment place-days, the total CHI days saved was 4.39 per place-day X $720=3161$ - the equivalent of 8.66 years in prison.

\section{Discussion}

This study was led by a "pracademic," a category of police professionals that may be the key drivers of implementation and compliance outcomes. As Barnes et al. (2020) summarised, "experiments can be conducted with a relatively small team of dedicated police pracademic researchers on patrol", the exact style in which this study was built and delivered. The pracademic approach balances the meticulous methodological standards rightly expected by science with the more real-world considerations of the practitioners at the front line. This approach also balances the power base observed by the practitioners undertaking the intervention who are more accustomed to formal power in role. Kirch (2007) states that "Culture trumps strategy", which is why this study's findings support the move to a more top-heavy and integrated approach to directing implementation in policing. This study has shown that hot spots policing can be achieved through implementation and control from police practitioners with the prerequisite knowledge and drive. This finding echoes those described by De Brito (2016) who found that "The primary mechanism seems to be the human element: differing management styles and capabilities". Everything observed shows that the consistent delivery of the intervention by a dedicated niche team is the reason for the successful implementation of this experiment.

This study has highlighted that violent crime can be deterred through the use of visible policing, a beacon of guardianship that generated the necessary influence on offenders without direct and traditional contact with them. As demonstrated in the 
decay of the treatment, its impact was so deep that it drove reductions not only within the study's key driver, violence, but all street visible crime.

The findings of the study were achieved with a modest allocation of $£ 22,750$ of Home Office Surge funding from an allocation of $£ 1,160,000$ to Essex Police in the year 2020/21. The initial findings were reported to the Home Office and Policing Minister in December 2020, resulting in Home Office analysis of the data and formal discussions on implementation. The subsequent dialogue and support this research provided has since driven the Violence Reduction Unit Funding Application Guidance (2021a) stipulating that $85 \%$ of allocated funding must be utilised to target hot spots using methods proven to deal with violent crime at micro-locations. The activity, methodology, and implementation have all been draw from this Randomised Control Trial (Operation Ark) and published via the Home Office to all forces within the Grip Funding: Hotspots Framework (2021).

A key point is that this study was all delivered using overtime. This dealt with a number of factors that would normally affect such interventions, such as the ability to be shown as additional officers undertaking a bespoke patrol and unavailable for redeployment by the Force Communication Room or Gold Commander. The use of Home Office funding and the requirement for quarterly returns provided the final additional layer of protection in the delivery.

\section{Conclusion}

The experiment has demonstrated significant reductions in crime harm and crime count for community violence, and the possibility to replicate the patrol strategy in other towns and cities.

The study's findings do tend to support one significant observation. The findings on compliance levels of $98.33 \%$ were a major outcome. The protection of the officers from re-deployment in a policing environment that still reacts to demand by all callers ensured that each day, all 8 harm spots allocated could be attended. The last element, and just as significant, is that the officers undertaking the patrol undertook the task knowing they were free from additions to their workloads through incident or crime attendance. These elements weighing on the minds of officers, coupled with the overwhelming cost benefit that dedicated officer patrols provided, lead us to recommend that for a successful and continuous benefit, forces should seek to implement dedicated (specialised) "crime suppression patrol" officers.

The findings of this experiment also provide evidence of strong implementation that further studies can replicate. From initial planning to pre-implementation, there was significant investment focussed on the administration of the experiment and the knowledge briefings delivered to those participating. Each officer was subject to an evidence-based policing input and demonstration of the tracking that would be undertaken. This coupled with deployment packs and daily feedback sought to provide the inclusivity that they were part of the study and subsequent findings. It is by such details that implementation can succeed, and serious violent crimes can be prevented. 
Funding This study was funded through "surge funding" from the Home Office for England and Wales, which saw Essex Police allocated £1,152,435 for the year 2020/21. It was also supported by the Senior Leader Degree Apprenticeship/Master of Studies programme in applied criminology and police management at the University of Cambridge. The first author is indebted to all of those officers who kindly agreed to participate in this study and delivered a quality policing experiment. He is particularly grateful to his apprenticeship mentor, Chief Superintendent Andrew Mariner.

Open Access This article is licensed under a Creative Commons Attribution 4.0 International License, which permits use, sharing, adaptation, distribution and reproduction in any medium or format, as long as you give appropriate credit to the original author(s) and the source, provide a link to the Creative Commons licence, and indicate if changes were made. The images or other third party material in this article are included in the article's Creative Commons licence, unless indicated otherwise in a credit line to the material. If material is not included in the article's Creative Commons licence and your intended use is not permitted by statutory regulation or exceeds the permitted use, you will need to obtain permission directly from the copyright holder. To view a copy of this licence, visit http://creativecommons.org/licenses/by/4.0/.

\section{References}

Ariel, B., Sherman, L. W., \& Newton, M. (2020). Testing hot-spots police patrols against no-treatment controls: Temporal and spatial deterrence effects in the London Underground experiment. Criminology, 58(1), 101-128.

Barnes, G. C., Williams, S., Sherman, L. W., Parmar, J., House, P., \& Brown, S. A. (2020). Sweet spots of residual deterrence: A randomized crossover experiment in minimalist police patrol. Posted at https://osf. io/preprints/socarxiv/kwf98/.

Braga, A. A., Weisburd, D. L., Waring, E. J., Mazerolle, L. G., Spelman, W., \& Gajewski, F. (1999). Problemoriented policing in violent crime places: A randomized controlled experiment. Criminology, 37(3), 541580 .

Braga, A. A., Papachristos, A., \& Hureau, D. (2014). The effects of hot spots policing on crime: An updated systematic review and meta-analysis. Justice Q, 31, 633-663.

Braga, A. A., Turchan, B., Papachristos, A. V., \& Hureau, D. M. (2019). Hot spots policing of small geographic areas effects on crime. Campbell Syst Rev, 15(3), 1-88.

De Brito, C., 2016. Will providing tracking feedback on hot spots patrols affect the amount of patrol dosage delivered? A level 4 experiment. Cambridge: Thesis submitted for the degree of MAster of Studies in applied criminlogy and police management, Institute of Criminology, Cambridge University.

Essex Police2 (2020). Performance Data, s.1.: s.n.

Francis, B., Soothill, K., Humphreys, L., \& Bezzina, C. A. (2005). Developing measures of severity and frequency of reconviction. Lancaster University Centre for Applied Statistics.

Greenfield, V. A., \& Paoli, L. (2013). A framework to assess the harms of crimes. Br J Criminol, 53(5), 864886.

House, P. D., \& Neyroud, P. W. (2018). Developing a crime harm index for Western Australia: The WACHI. Cambridge Journal of Evidence-Based Polciing, 2, 70-94.

Ignatans, D., \& Pease, K. (2015). Taking crime seriously: Playing the weighting game. Policing, 10(3), 184 193.

Karrholm, F., Neyroud, P., \& Smaaland, J. (2020). Designing the Swedish crime harm index: An evidencebased strategy. Cambridge Journal of Evidence Based Policing, 4, 15-33.

Kirch, D. G., 2007. Culture and the courage to change - Association of American Medical Colleges President's address 2007 annual meeting.

Koper, C. S. (1995). Just enough police presence: Reducing crime and disorderly behaviour by optimizing patrol time in crime hot spots. Justice Q, 12(4), 649-672.

Mitchell, R. J. (2017). The usefulness of a crime harm index: Analyzing the Sacramento hot spot experiment using the California Crime Harm Index (CA-CHI). J Exp Criminol, 15(1), 103-113.

National Police Chiefs Council. (2016). Policing vision 2025. NPCC.

Neyroud, P. W. (2016). The ethics of learning by testing: The police professionalism and researching the police (1st ed.). Routledge. 
Office for National Statistics (2020). Office for National Statistics. [Online] Available at: https:// www.ons.gov.uk/peoplepopulationandcommunity/crimeandjustice/datasets/ crimeseverityscoreexperimentalstatistics. Accessed Nov 2020.

Ratcliffe, J. H., 2015. Towards an index for harm-Focussed policing. Policing , 9(2), pp. 164-183.

Ratcliffe, J., Taniguchi, T., Groff, E., \& Wood, J. (2011). The Philadelphia foot patrol experiment: A randomized controlled trial of police patrol effectiveness in violent crime hotspots. Criminology, 49(3), 133-157.

Sherman, L. W. (1990). Police crackdowns: Initial and residual deterrence. Crime Justice, 12, 1-48.

Sherman, L. W. (1995). Hot spots of crime and criminal careers of places. In E. Eck \& D. Weisburd (Eds.), Crime and place (pp. 35-52).

Sherman, L. W. (2013). The rise of evidence-based policing: Targeting, testing and tracking. Crime and Justice: A Review of Research, 42, 377-452.

Sherman, L. W., 2019. Trinidad randomised controlled trial. M.St. Lectures. Cambridge, Cambridge University Senior Police Leadership Program .

Sherman, L. W., \& Cambridge University Associates. (2020). How to count crime: The Cambridge Harm Index Consensus. Cambridge Journal for Evidence Based Policing, 4, 1-14.

Sherman, L. W., Gartin, P. R., \& Buerger, M. E. (1989). Hot spots of predatory crime: Routine activities and the criminology of place. Criminology, 27(1), 27-56

Sherman, L. W., \& Weisburd, D. (1995). General deterrent effects of police in crime "hot spots". Justice Quarterly, 12(4), 625-648.

Sherman, L. W., et al. (1998). Preventing crime: What works, what doesn't, whats promising. National Institute of Justice.

Sherman, L. W., Neyroud, P. W., \& Neyroud, E. (2016). The Cambridge crime harm index: Measuring total harm from crime based on sentencing guidelines. Policing: A Journal of Policy and Practice, 10(3), 171183.

Publisher's Note Springer Nature remains neutral with regard to jurisdictional claims in published maps and institutional affiliations. 